\title{
Satureja macrostema: situación ambiental, conocimiento local y roles de género
}

\section{Satureja macrostema: environmental situation, local knowledge and gender roles}

Tomás Ortega-Ortega' y Verónica Vázquez-García'

\begin{abstract}
1 Programa de Estudios para el Desarrollo Rural. Colegio de Postgraduados, Campus Montecillo. Correos electrónicos: verovazgar@yahoo.com.mx, tommyortega2002@yahoo.com.mx
\end{abstract}

\section{RESUMEN}

Los Recursos Forestales No Maderables (RFNM) contribuyen a la seguridad alimentaria de comunidades forestales. En México se aprovechan aproximadamente 1000, pero existen pocos trabajos que sistematicen conocimientos locales y el papel de las mujeres en su aprovechamiento. Este artículo persigue tres objetivos: describir las condiciones de distribución, luz y suelo de un RFNM llamado "poleo" Satureja macrostema (Benth.) Briq.; documentar los conocimientos locales sobre esta planta; analizar diferencias de género en términos de acceso, uso y comercialización. El trabajo fue realizado en San Miguel Mixtepec, comunidad zapoteca de los Valles Centrales de Oaxaca. Para obtener información se utilizó una variedad de métodos: análisis de suelo y cobertura de dosel, observación participante, entrevistas y talleres. Se concluye que el poleo se distribuye de forma discontinua, bajo cobertura de dosel cerrado, en suelos moderadamente ácidos y ricos en materia orgánica. Existen conocimientos locales sobre el proceso reproductivo de la planta que fomentan su permanencia. La planta tiene usos rituales, ornamentales, alimenticios y medicinales. Los hombres predominan en los dos primeros usos y las mujeres en los dos últimos. La comercialización está predominantemente en manos femeninas, específicamente de las "viudas", es decir, mujeres adultas con hijos/as y sin pareja. El poleo ingresa al mercado regional en condiciones de informalidad y bajo precio, pero su trueque o venta aporta diversidad a la dieta y es un buen ejemplo de la amplia gama de actividades de subsistencia que realizan las mujeres de comunidades forestales del país.

PALABRAS ClAVE: comercio, género, Recursos Forestales No Maderables, saberes, uso.

\section{ABSTRACT}

Non Timber Forest Products (NTFP) contribute to the food security of forest communities. Around 1000 of those are used in Mexico, but little information is available on local knowledge and women's roles in NTFP management. This paper pursues three objectives: to describe the distribution, light and soil conditions of a NTFP called "poleo" Satureja macrostema (Benth.) Briq.; to document local knowledge on this plant; to analyze gender differences in terms of access, use and trade. Research was conducted in San Miguel Mixtepec, a Zapotec community of the Central Valleys of Oaxaca. Methods include soil and canopy analysis, participant observation, interviews and workshops. Poleo grows under a closed canopy, in slightly acid, organically rich soils. Local knowledge on the plant's reproductive process contributes to its permanence. The plant is used for community rituals, as ornament, food and medicine. Men predominate in the first two uses and women in the remaining ones. Trading activities are female-dominated, mostly by 'widows' (adult women with children and no partner). The plant is informally traded in regional markets at very low prices. However, its barter or sale contributes to diversify local diets and is a good example of women's subsistence activities in the forest communities of Mexico.

KEY WORDS: trade, gender, Non Timber Forest Products, knowledge, uses. 


\section{INTRODUCCIÓN}

En México, alrededor de 140 millones de hectáreas (73\% del territorio nacional) tienen cobertura forestal. Los ecosistemas con mayor porcentaje son matorrales xerófilos (41\%), bosques templados (24\%) y selvas (23\%) (INE, 2009). Los bosques albergan $81 \%$ de las 25 mil especies de plantas vasculares y $75 \%$ de las 1352 especies vertebradas que existen en México (Bray et al., 2007), asunto que coloca al país en el cuarto lugar mundial en biodiversidad (Sánchez y García, 2008).

El uso medicinal, alimenticio, ritual, ornamental o artesanal de los Recursos Forestales No Maderables (RFNM) contribuye a la seguridad alimentaria y bienestar de comunidades forestales (Martínez y Masera, 2012). RFNM como orégano, candelilla, raíz de zacatón, ixtles de palma, agaves, cactáceas y lechuguilla tienen un mercado establecido en manos de pequeñas industrias. Se aprovechan alrededor de 1000 RFNM y la información sobre cada uno de ellos es limitada (Musálem, 2007). Merino et al. (en prensa) mencionan la resina, tierra de monte, carbón, palmas, plantas de ornato, agaves y hongos, resaltando la informalidad y el "sub-registro" en su proceso de cosecha y comercialización, "a pesar del importante potencial de esta producción”. Chapela y Madrid (2008) también señalan la carencia de datos y políticas que impulsen esta importante área del aprovechamiento forestal.

El poleo es un RFNM de tipo arbustivo con olor a menta que crece en climas templados de encino (Quercus), pino (Pinus) y oyamel (Abies religiosa) (Figs. 1 y 2). Se distribuye en zonas montañosas y boscosas al occidente del país, abarcando los estados de Oaxaca, Guerrero, Colima, Jalisco, Michoacán y el eje neovolcánico del Estado de México, Puebla y Morelos. Los purépechas lo conocen como nurhitini o nurite; los zapotecos le llaman hierba o rosa de borracho, poleo, guiezza y quieutzu; los nahuas le nombran cuencuenzpatli. También se le conoce como toche, garañona, té de monte, atóchietl, tragorigano, quauhnahuacense, toronjil, tunché y tarepe (Turner, 2008; Redowski y Calderón, 2010).

En los mercados de los Valles Centrales de Oaxaca, el poleo se vende e intercambia por alimentos. Tiene usos medicinales (controlar malestares estomacales y la resaca producto del consumo excesivo de bebidas embriagantes), alimenticios (en forma de té, agua de tiempo, condimento o quelite), rituales y ornamentales, por ejemplo, se reparte en forma de pequeños manojos y se utiliza para adornar edificios en bodas, fiestas patronales, día de muertos y año nuevo. Todo esto hace del poleo un RFNM multipropósito de "interés social y económico" (Aguilar, 2002:44).

La venta de RFNM constituye una significativa fuente de ingresos para las mujeres más pobres, de mayor edad y con escasos niveles de educación formal (Schreckenberg et al., 2006; Ahenkan y Boon, 2011; Djoudi y Brockhaus, 2011; Mai et al., 2011). Tales ingresos también se encuentran en condición de sub-registro ante la existencia de

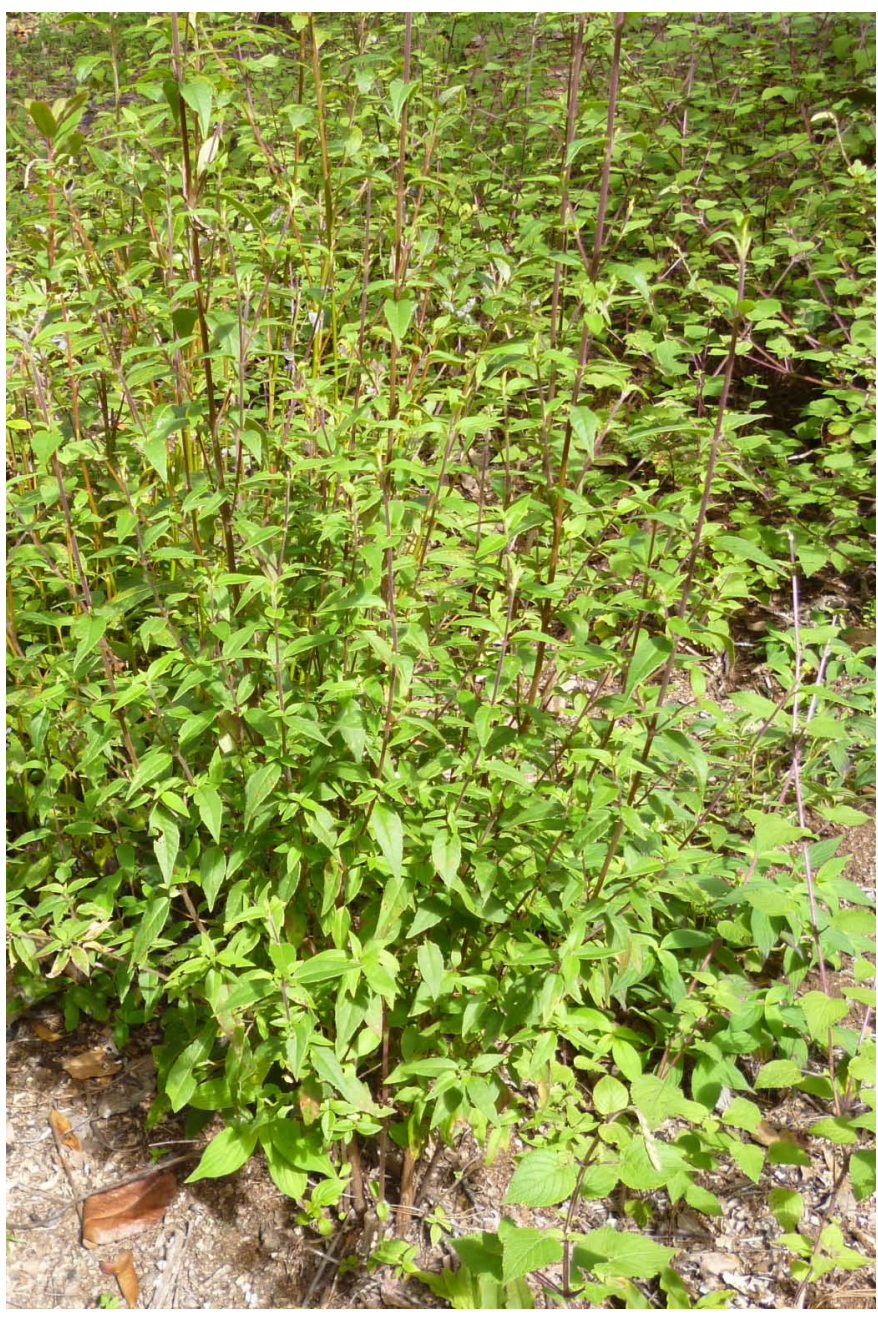

FIGURA 1. Planta de poleo en fase vegetativa. 


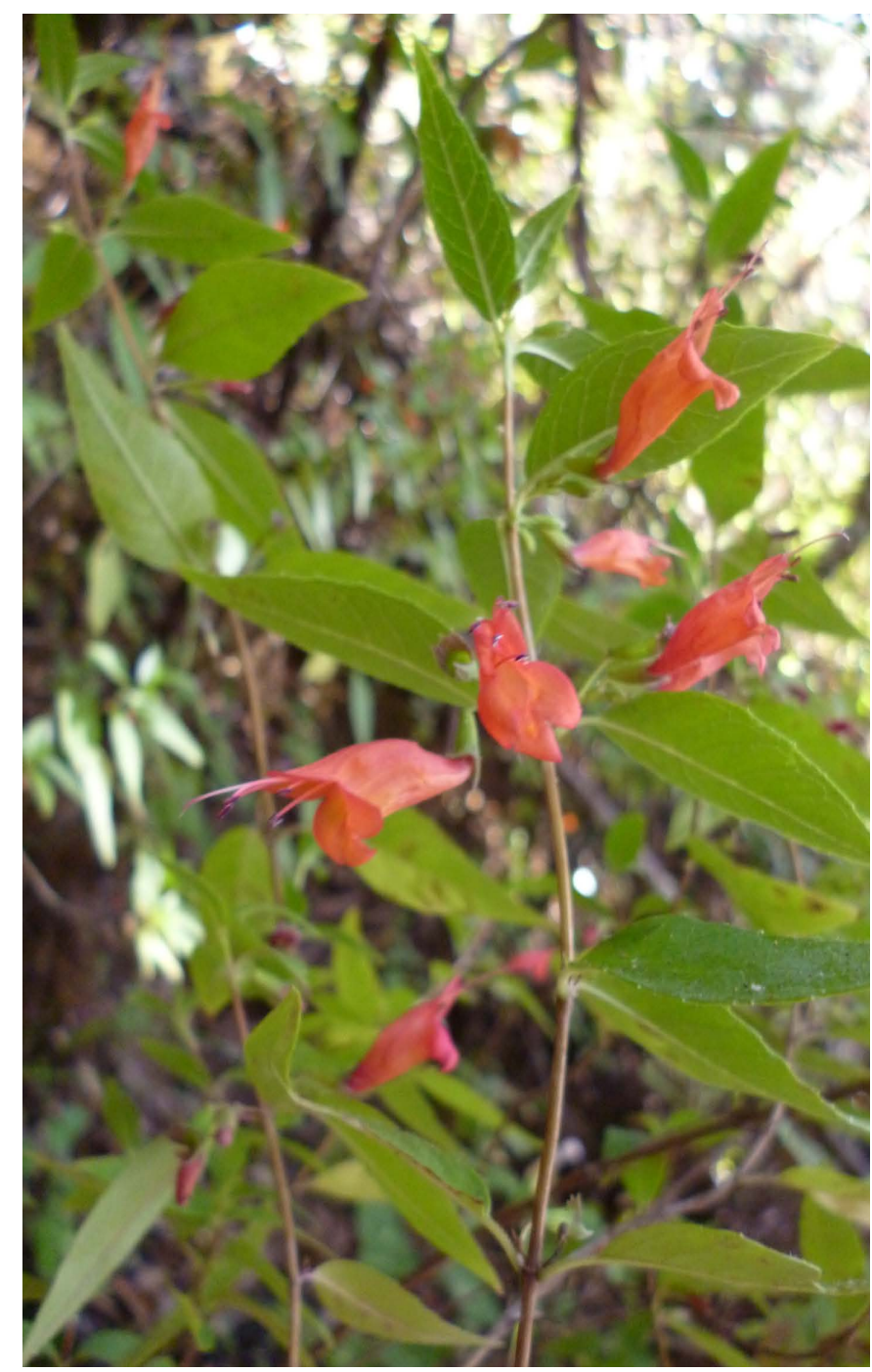

FIGURA 2. Planta de poleo en fase reproductiva.

subsidios gubernamentales, remesas y venta de productos agrícolas, pecuarios o madereros (Quiroz, 1999; Schreckenberg y Marshall, 2006; World Bank, 2009; Shackleton et al., 2011). Por tal motivo, resulta necesario documentar el papel de las mujeres en el aprovechamiento de RFNM con la finalidad de promover el desarrollo integral y sustentable de comunidades forestales. Atendiendo esta preocupación, el presente artículo persigue los objetivos que se detallan a continuación.

\section{Objetivos}

Describir las condiciones de distribución, luz y suelo que favorecen el crecimiento y reproducción del poleo (Satu- reja macrostema), RFNM aprovechado en los Valles Centrales de Oaxaca.

Documentar los conocimientos locales sobre la época y formas de extracción más favorables para la planta.

Analizar las diferencias de género en torno a tres aspectos: el uso del poleo, el acceso a la planta y su proceso de mercadeo.

\section{ZONA DE ESTUDIO}

El estudio se realizó en el municipio de San Miguel Mixtepec (SMM), distrito de Zimatlán, región Valles Centrales, Oaxaca. Tiene una superficie de $73 \mathrm{~km}^{2}$, donde $92,12 \%$ es bosque de pino-encino (INEGI, 2005). La población total del municipio es de 3245 habitantes (1571 hombres y 1674 mujeres) distribuidos en 586 hogares. La mayoría (77\%) habla zapoteco.

SMM se caracteriza por ser una comunidad forestal, cuya superficie de uso de suelo asignado a la agricultura es de 3,86\% (INEGI, 2005). Tal actividad se desarrolla en condiciones de ladera y con prioridad para la siembra de frutales de clima templado (durazno, granada china, manzana criolla, pera), además de maíz y frijol. En 2010 se produjeron $3469 \mathrm{~m}^{3}$ de madera, 3208 toneladas de maíz y 249 toneladas de frijol (INEGI, 2010). El municipio es considerado de muy alta marginación (Conapo, 2011).

La tenencia de la tierra es comunal, con un predominio masculino absoluto (772 comuneros y ninguna comunera). Tanto el Comisariado de Bienes Comunales (СВC) como el Comité de Vigilancia (CV) está totalmente compuesto por hombres. El bosque se encuentra bajo un programa de aprovechamiento forestal cuya superficie es de 2599 hectáreas en producción para el periodo 2008-2018. Además cuenta con un área de conservación y aprovechamiento restringido de 2879 hectáreas (Semarnat, 2009).

\section{MATERIALES Y MÉTODOS}

El trabajo de campo se realizó entre junio de 2012 y marzo de 2013. Primero se visitaron cuatro mercados de los Valles Centrales de Oaxaca (Zimatlán de Álvarez, Zaachila, Ocotlán de Morelos y Ayoquezco de Aldama) para observar la dinámica de comercialización del poleo. 
También se acudió a SMM para realizar entrevistas y obtener la autorización del CBC para realizar la investigación.

Posteriormente se seleccionaron y geo-referenciaron tres lugares del territorio de SMM donde crece el poleo (Fig. 3). Cada sitio tuvo una extensión de 100 m x 100 m ubicados a tres altitudes distintas, para tomar muestras del suelo en forma de zig-zag a una profundidad de $20 \mathrm{~cm}$. Se obtuvieron cinco sub-muestras por sitio, que fueron mezcladas para tener una sola muestra por sitio. Se calculó la cobertura del dosel bajo el cual crece la especie mediante el uso de un densiómetro esférico, para lo cual se ubicaron nueve puntos en cada sitio; en cada uno se tomaron cuatro lecturas (al norte, sur, este y oeste respectivamente). En todos estos recorridos se ubicó la especie en su hábitat natural, se identificaron los parajes donde crece, se obtuvieron datos para la descripción de distribución y se observó la dinámica de cosecha.

También se utilizaron tres técnicas de investigación social: observación participante, talleres y entrevistas. La primera permite registrar la realidad de forma efectiva y directa; los talleres son un medio idóneo para hacer diagnósticos, identificar problemáticas y socializar información entre personas que no tienen acceso a medios de comunicación (periódicos, internet) o incluso no saben leer y escribir; las entrevistas ayudan a identificar significados y patrones de comportamiento en torno a determinada actividad, por ejemplo el uso del poleo. En su modalidad de semi-estructuradas, las preguntas parten de

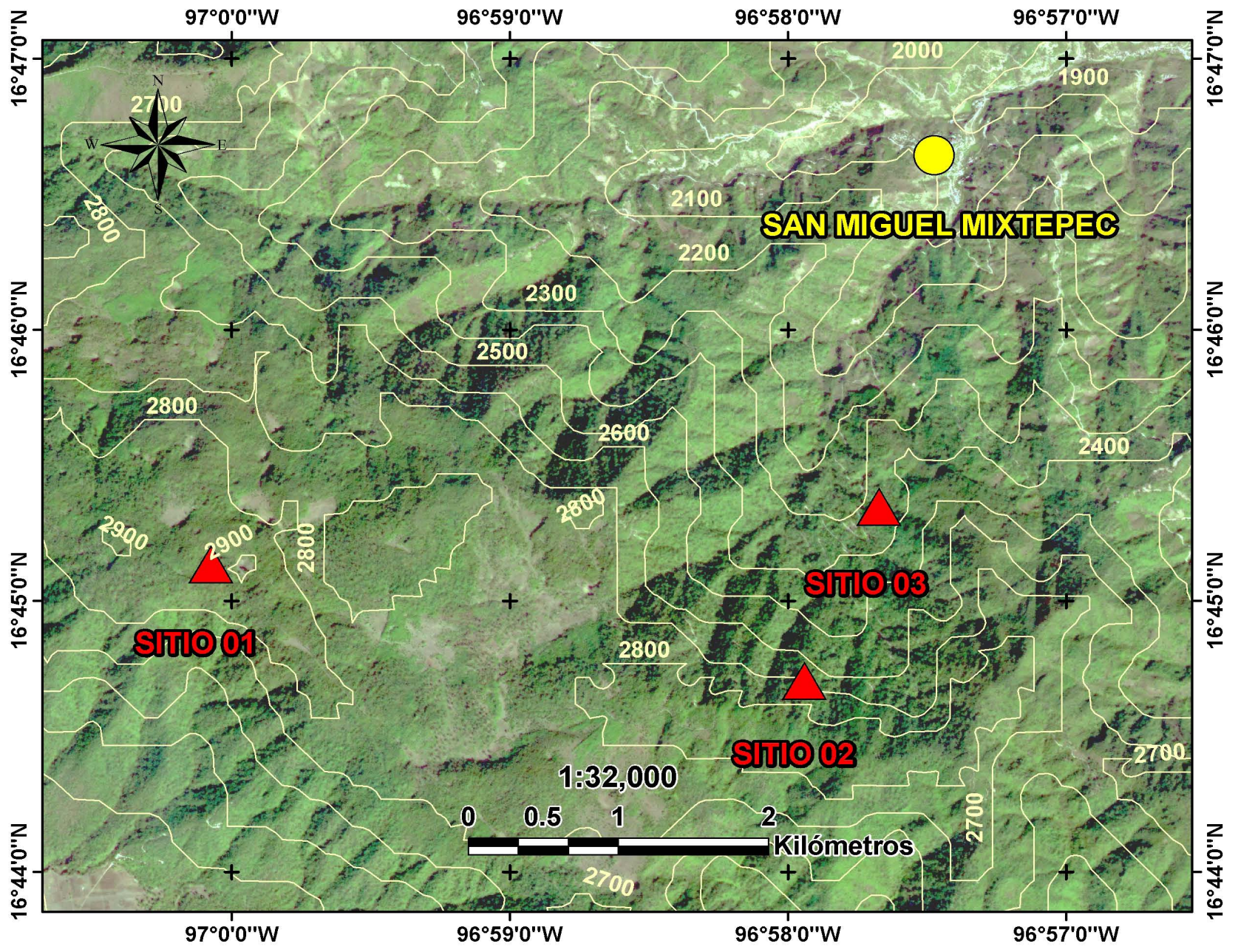

FIGURA 3. Sitios de muestreo. 
temáticas específicas y se van desarrollando nuevas a medida que se brinda la información solicitada (Sandoval, 2002). La combinación de métodos permitió triangular la información obtenida.

La observación participante se realizó de manera permanente, registrando todos los datos posibles sobre el poleo. La fiesta de año nuevo, que coincide con el ingreso de nuevas autoridades al gobierno municipal, fue observada de principio a fin, durante varios días, desde el proceso de extracción de la planta hasta su arreglo y reparto el día de la fiesta.

Se organizaron dos talleres, el primero con diez hombres con algún cargo comunitario, ya sea en el poder agrario o municipal: integrantes del $\mathrm{CBC}$, del CV, representantes de agencias o núcleos rurales. En el segundo participaron 19 mujeres. En ambos talleres se abarcaron los siguientes temas: épocas del año en las que se encuentra y cosecha el poleo, condiciones en las que crece, formas y cantidades de cosecha, usos que se le da a la planta y proceso de comercialización.

Finalmente, se entrevistó a nueve hombres y cinco mujeres con el fin de profundizar sobre las condiciones que favorecen el crecimiento de la especie, los diversos usos y el orden de género que rige el acceso a la planta. Cinco de los nueve hombres tenían algún cargo: dos policías municipales; un ex presidente del СВC (período 20092012); un integrante del comité de padres de familia de la escuela primaria; y un servidor público en el Área de Desarrollo Agropecuario de Zimatlán. Ninguna de las cinco mujeres entrevistadas tenía cargos comunitarios en el momento de la entrevista.

\section{RESULTADOS Y DISCUSIÓN}

\section{Condiciones de distribución, luz y suelo}

El poleo crece de manera natural entre los $2345 \mathrm{msnm}$ y $2900 \mathrm{msnm}$. Fue localizado en parajes específicos conocidos localmente como Mogote del Chaneque, Nevería, Nerela, Jarro Grande, Jarro Chico y Tierra Colorada. Los parajes se caracterizan por tener manantiales permanentes de aguas, vegetación abundante de pino y encino, suelos ricos en materia orgánica y temperaturas relativamente bajas (Umafor, 2009).

El poleo se distribuye de manera discontinua por debajo del dosel vegetal principal, por lo tanto es una especie que forma parte del sotobosque. Ahí se presentan condiciones específicas que favorecen su crecimiento. Generalmente estos espacios albergan una alta riqueza florística endémica (Challenger y Soberón, 2008; Rzedowski y Calderón, 2010; Villaseñor, 2010).

De acuerdo con los talleres y las entrevistas, el poleo crece debajo del encino, de la combinación de pino y encino y, ocasionalmente, debajo del pino. "Por lo regular, hay abajo de los encinos, entre encino y pino, es donde hay". Se desarrolla bajo cobertura de dosel cerrado, esto implica que el poleo aprovecha al máximo la poca luz solar que atraviesa la cobertura para la elaboración de compuestos aromáticos y la fotosíntesis (Valladares 2006; Umafor, 2009) (Tabla 1).

Las temperaturas de los bosques de pino y encino tienden a ser frías (Challenger y Soberón, 2008). En el municipio se presenta una media anual de $14{ }^{\circ} \mathrm{C}$ a $16{ }^{\circ} \mathrm{C}$; durante el invierno la media mínima alcanza los $0{ }^{\circ} \mathrm{C}$ y en

TABla 1. Características de los sitios muestreados.

\begin{tabular}{lcclcll}
\hline Sitio & LN & LW & $\begin{array}{c}\text { Altitud } \\
m \text { snm }\end{array}$ & $\begin{array}{c}\text { Cobertura del dosel } \\
\text { (\%) }\end{array}$ & MH.O. \\
\hline 1 & $16^{\circ} 45^{\prime} 07,8^{\prime \prime}$ & $97^{\circ} 00^{\prime} 04,4^{\prime \prime}$ & 2847 & 83,62 & 6,0 & 11,9 \\
2 & $16^{\circ} 44^{\prime} 42,3^{\prime \prime}$ & $96^{\circ} 57^{\prime} 56,4^{\prime \prime}$ & 2727 & 92,49 & 6,0 & 9,2 \\
3 & $16^{\circ} 45^{\prime} 20,8^{\prime \prime}$ & $96^{\circ} 57^{\prime} 40,3^{\prime \prime}$ & 2345 & 86,8 & 6,2 & 5,4 \\
\hline
\end{tabular}

M.O.: Materia orgánica

Fuente: elaboración a partir de datos de campo y análisis de suelo. 
los meses de abril y mayo la media máxima puede llegar a los $26{ }^{\circ} \mathrm{C}$ (Umafor, 2009). Esta condición desacelera la descomposición de la materia orgánica, proceso que acidifica ligeramente el suelo, aunque la variación en el $\mathrm{pH}$ también depende del origen del suelo ahí presente (Labrador, 2001; Challenger y Soberón, 2008).

De acuerdo con la NOM-021-RECNAT-2000 (Semarnat, 2001), el pH de las tres muestras medido en agua con una relación suelo/solución de 1:2, presentó una clasificación de moderadamente ácido. Las medidas obtenidas se encuentran en un intervalo que favorece la asimilación de macro y micronutrientes (Tabla 1).

La acumulación de materia orgánica descompuesta provoca la presencia de suelos oscuros debido a la alta presencia de humus. Las entrevistas señalan que los suelos negros favorecen el crecimiento y desarrollo del poleo: "en pura tierra negra se da buena la mata”. En suelos donde no se tiene esta coloración, el crecimiento de la planta es precario o inexistente: "hay tierra roja, pero como que no se dan mucho".

El parámetro de materia orgánica de los tres sitios fue obtenido por el método Walkley-Black. Las concentraciones se ubican en alto contenido $(3,6-6,0)$ para el sitio 3 y muy alto $(>6,0)$ para los sitios 1 y 2 , de acuerdo con la clasificación de la NOM-021-RECNAT-2000 que corresponde a suelos no volcánicos (Semarnat, 2001). Esto en virtud de que el INEGI (2005) clasifica el área muestreada con presencia de suelos luvisol y cambisol. El sitio 1, que corresponde a la parte más alta (2847 msnm) y menos vulnerable a la intervención humana, se caracterizó por tener la mayor concentración (Tabla 1). La alta acumulación de materia orgánica descompuesta favorece la presencia silvestre de la especie.

La especie está mejor conservada en Mogote del Chaneque y Nevería, que son las partes más altas: “yo pienso que porque está... más alto y más frío y luego es donde casi no llegan las personas a cortarla, por eso hay siempre ahí en ese lugar”. Sin embargo, en los recorridos sí se constataron indicios de cosecha en estos parajes.
Época y forma de cosecha: un sistema de saberes De febrero a mayo la planta entra en un proceso de defoliación y reposo. De mayo a agosto, con las lluvias, la planta retoña y la parte vegetativa se regenera (Aguilar $e t$ al., 2005). De septiembre a enero está lista para ser recolectada. En estos meses los brotes han alcanzado una longitud de $50 \mathrm{~cm}$ a $80 \mathrm{~cm}$, que es la medida más adecuada para los distintos usos que se le dan a la planta.

Los pueblos indígenas han desarrollado sistemas de saberes relacionados con el manejo y aprovechamiento de RFNM (De Walt, 1999; De la Peña e Illsey, 2001). Tal es el caso del poleo. En la temporada de lluvias se reduce al máximo su recolección porque la comunidad está concentrada en trabajos agrícolas y porque los tallos no tienen la longitud adecuada. "Durante la época de lluvias dejamos que la planta retoñe". La cosecha se realiza de septiembre en adelante, generalmente hasta enero. Se trata de una actividad estacional, bien coordinada con el ciclo de siembra de maíz, que termina precisamente en septiembre, cuando se cosechan los primeros elotes. El aprovechamiento del poleo representa ingresos adicionales a las actividades agrícolas de la comunidad. La complementariedad entre actividades agrícolas y de recolección forestal ha sido documentada en otros estudios (Schreckemberg et al., 2006).

La floración del poleo comienza en el mes de noviembre; esta etapa fenológica coincide con la época de mayor extracción. La gente tiene cuidado en no recolectar los tallos que están en floración para proteger la fase reproductiva de la especie y su semilla. Así lo dijo un entrevistado: "si lo cortamos con flor vamos a echar a perder semilla... no conviene usarla cuando tiene flor... siempre lo buscamos en parte donde están así en hoja verde, donde todavía no tiene flor... esa es... la regla que tenemos, pues". De acuerdo a una entrevistada, la clientela prefiere las ramas verdes, sin florecer: "ya cuando [tiene] flores ya las hojas son rosado-amarillas, y cuando son tiernitos, las hojas están todas verdes pues, todas verdes, y es lo que le gusta a la gente cuando lo llevan a vender... cuando lo usan en los nacimientos para las posadas... que se vean verdes donde van a dar una posada”. Según Alexiades y Shanley (2004), la estrategia de cosecha influye en el 
estado del recurso. En el caso del poleo, la cosecha de tallos libres de floración permite su reproducción y por consiguiente, la permanencia del recurso en el bosque. Se constata que en SMM existen conocimientos sobre el proceso reproductivo de la planta que fomentan su permanencia.

La planta generalmente se cosecha con la mano: "hemos visto que cuando lo cortamos con la mano se retoña otra vez, no se muere la raíz". Así se fomenta el surgimiento de retoños: "lo vas quebrando... con la mano nomás... donde quiebras, ahí van a crecer, en vez de uno, van a crecer dos [retoños de poleo]". Dada la consistencia leñosa del tallo, no es difícil cortar con la mano: “es frágil la rama, se quiebra fácilmente, por eso lo cortan... batallan más usando una herramienta" (Figs. 4 y 5). La norma establece evitar la tijera: "la planta que se corta con...

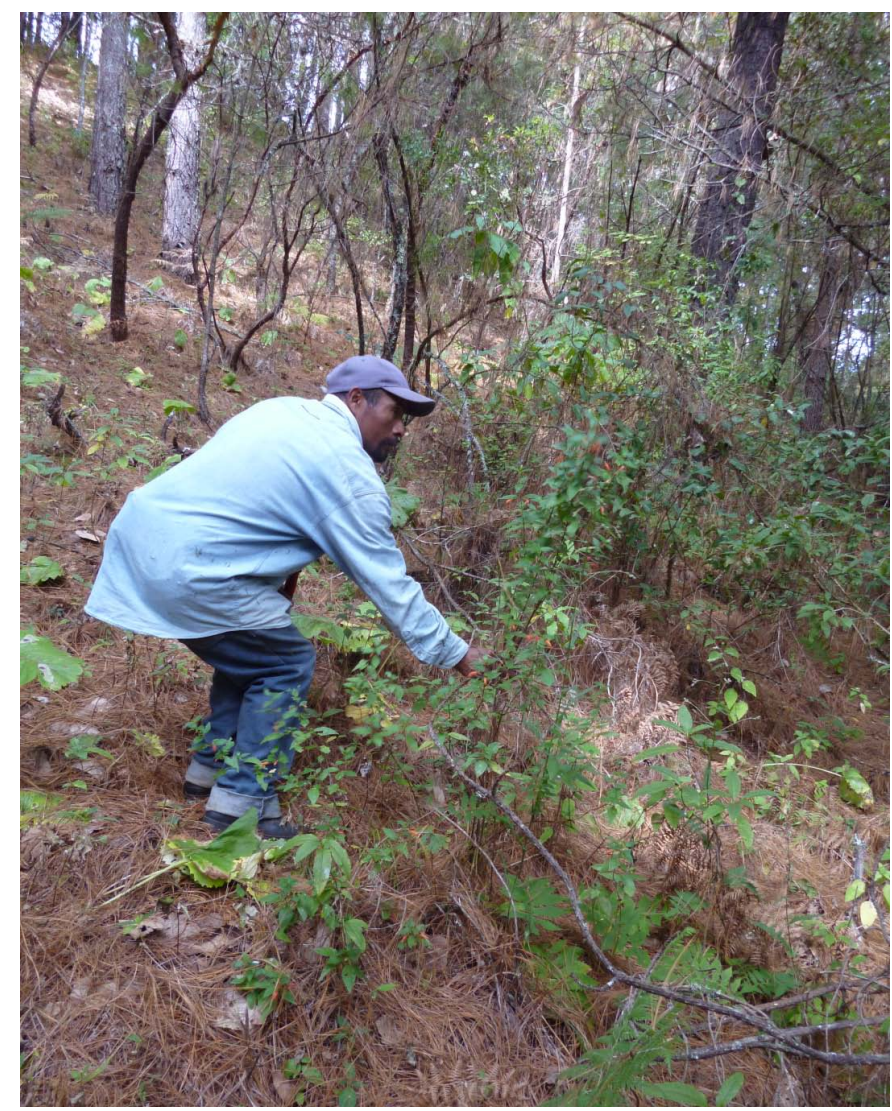

FIGURA 4. Hombre recolectando poleo con la mano. tijera o con... cualquier tipo de fierro, no... confiamos mucho, porque a veces se seca". La gente sabe que cosechar con la mano favorece el desarrollo de nuevos brotes. En cambio, la utilización de una tijera o de otro instrumento punzocortante puede ser fuente de proliferación de enfermedades y ocasionar la muerte de la planta.

El poleo responde positivamente a la intervención humana: puede crecer cerca del maíz ya que los "roces" favorecen su desarrollo. La cosecha de madera también lo ayuda: "cuando se corta la madera, ahí... retoña mucho". Si alguien se encuentra "poleo avejentado", lo poda para que se renueve: "uno mismo le da su mantenimiento... porque hay... poleos que... ya están secos... pues tienes que cortar abajo para que vuelva a nacer... nuevo poleo, porque si lo dejas nomás pura rama... se va a secar... tú tienes que cortarlo y ya vuelve a nacer”.

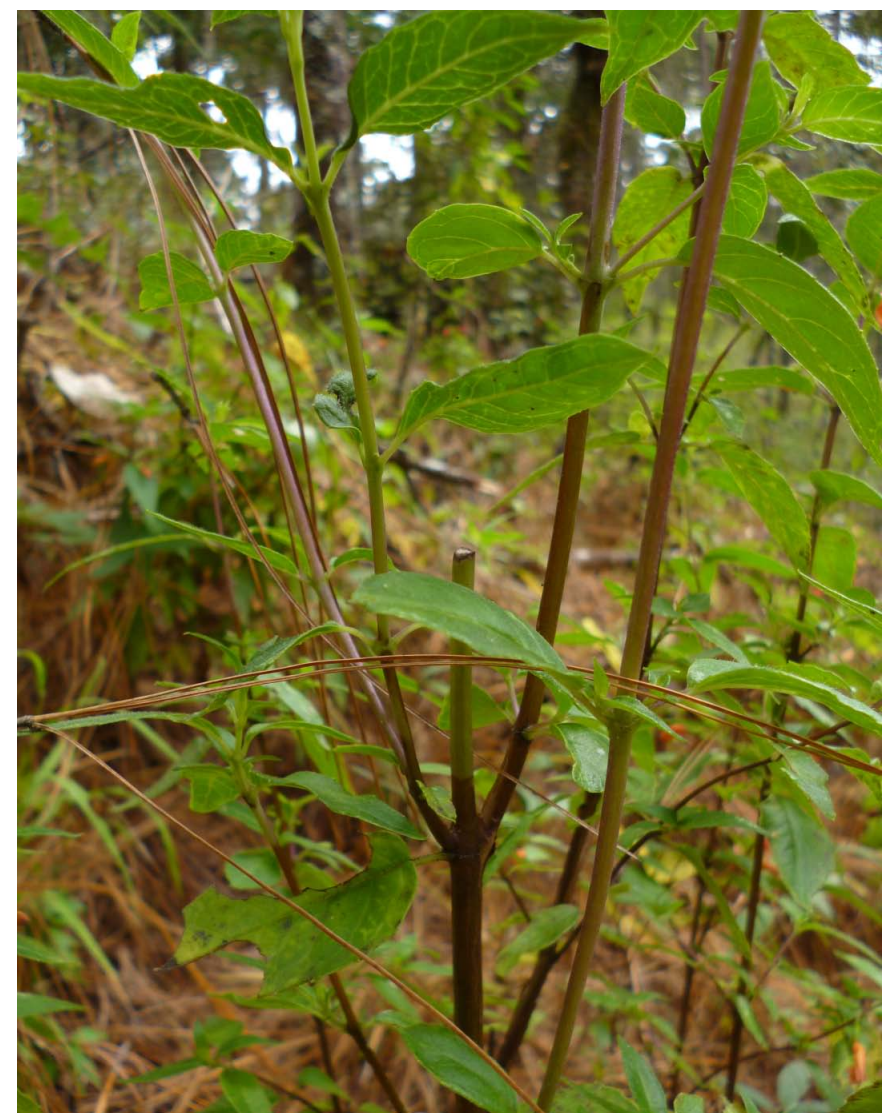

Figura 5. Planta de poleo con nuevos brotes a partir del tallo recolectado. 


\section{Usos diferenciados de género: lo público y lo privado}

Se identificaron cuatro usos: ritual y ornamental (para fiestas comunitarias); alimenticio y medicinal (para uso familiar). Es decir, el poleo es una planta del espacio público (ritual y ornamental) y del privado (medicinal y alimenticio). Puesto que los hombres están culturalmente asociados con el primero, y las mujeres con el segundo, los usos de la planta también están diferenciados por género. En esta sección se analiza cada uno de ellos.

El poleo se utiliza en diferentes festividades como "símbolo de alegría", es decir, de unidad y celebración comunitaria. Las más importantes son: la fiesta de año nuevo (1 de enero), mayordomía de San Miguel Arcángel (28 de septiembre), día de muertos (31 de octubre al 2 de noviembre), posadas (16 al 26 de diciembre) y bodas (fechas diversas). La de año nuevo coincide con el ingreso de las nuevas autoridades del gobierno municipal (cabildo) y agrario $(\mathrm{CBC})$. En definitiva es la más importante y para la cual se cosecha más poleo (Tabla 2), por lo que el análisis se centrará en ella.

En la semana previa a la fiesta de Año Nuevo se integra un equipo de hombres de diversas edades. El día 31 de diciembre, muy temprano por la mañana, salen a cosechar el poleo. Regresan por la tarde y después de comer arreglan los ramos que serán entregados a las autoridades y al resto de la población (Fig. 6). También adornan la iglesia y las mesas donde estarán sentadas las autoridades salientes y entrantes. Al día siguiente la repartición de ramos se acompaña con dianas y chilenas instrumentadas con música de viento. Se trata de una ceremonia que celebra el comienzo del año con nuevas autoridades municipales y agrarias, ambos poderes totalmente masculinos. Las esposas de las nuevas autoridades preparan y reparten los alimentos desde varios días antes pero no dan ningún discurso ni figuran como autoridad (Fig. 7).

El uso alimenticio del poleo es bastante más cotidiano y su preparación corresponde a las mujeres. Se identificaron cuatro maneras de consumirlo. Se utiliza para tomarlo en té, para condimentar la comida (frijoles y
TABLA 2. Fiestas comunitarias y extracción de poleo.

\begin{tabular}{ccc}
\hline Festividades & $\begin{array}{c}\text { Quién lo extrae } \\
\text { (mozos) }\end{array}$ & $\begin{array}{c}\text { Cantidad } \\
\text { aproximada } \\
\text { (brazadas*) }\end{array}$ \\
\hline Fiesta de Año Nuevo & 8 & 12 \\
$\begin{array}{c}\text { Mayordomía de San } \\
\text { Miguel Arcángel }\end{array}$ & 2 & $1-2$ \\
Fiesta de Navidad & 2 & 1 \\
Bodas & 2 & 2 \\
\hline
\end{tabular}

* Una brazada equivale a lo que se puede tomar con ambos brazos y atar con una cuerda, su peso aproximado es de 20 kg, fuente: taller con hombres, noviembre de 2012

tamales), cuando no hay nada más que tortilla ("con pura tortilla, como verdura”) y como agua de tiempo, cuando el té está frío. La más importante es el té: "por el gusto, es saludable... porque es planta del campo... es sabrosa". "Lo... usamos mucho más que café... para nosotros pues es... más puro". Esta multiplicidad de usos alimenticios fue documentada en el taller de las mujeres, lo cual refleja los roles culturalmente asignados a ellas y los conocimientos que han desarrollado para cumplirlos (Aguilar, 2007). Resalta el uso del poleo como quelite, un alimento de emergencia al cual se recurre cuando no hay nada más para acompañar la tortilla que aporta diversidad a la dieta en forma de vitaminas y minerales (Vázquez-García et al., 2004).

Los usos medicinales del poleo fueron mencionados tanto por mujeres como por hombres. Ambos se enfocaron en usos "ordinarios" ya que los "especializados" (que curan padecimientos más serios) generalmente están en manos de curandero/as de ambos sexos (Leach, 1994). Las participantes del taller documentaron la utilidad del poleo para controlar padecimientos estomacales. Las de mayor edad ( $\geq 51$ años) resaltaron además su utilidad para el trabajo de parto y las jóvenes adultas ( $\leq 30$ años) se enfocaron en enfermedades respiratorias relacionadas con el cuidado de hijas e hijos pequeños, situación que refleja 


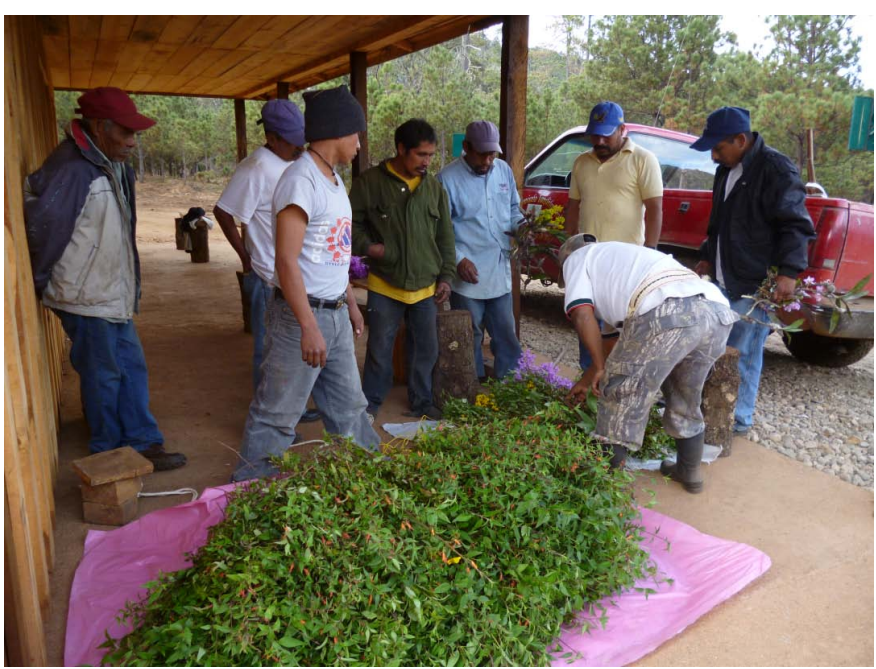

FIGURA 6. Hombres de SMM recolectando poleo para la fiesta de la comunidad.

conocimientos diferenciados no sólo de acuerdo al género, sino también a la edad. Por su parte, los hombres se enfocaron en el control de la resaca, uso que hace famoso al poleo en los Valles Centrales donde también se le conoce como rosa, hierba o flor de borracho. Un informante mencionó el control de la fiebre: "agua de mezcal caliente con... poleo, [se aplica en] toda la rodilla y la planta de los pies, por la espalda de uno, en la frente, el cuello y luego tapas [con] dos o tres cobijas, pero primero Dios ya amaneces al otro día, ya se va la calentura”. Algunas investigaciones han revelado que el poleo es una fuente importante de antioxidantes naturales (Alonso, 2009; Pérez, 2012). El poleo es importante para el cuidado de la salud porque se encuentra disponible localmente y no es necesario pagar por él.

Como puede verse, la planta tiene múltiples usos, razón por la cual posee valor comercial en los Valles Centrales de Oaxaca y necesariamente invita a conceptualizar al bosque de SMM como un sitio de "múltiples usuarios" (Schminck, 1995). Según esta autora, cada "actor" o "grupo social" tiene una "racionalidad" particular para el uso del bosque, las cuales "a menudo están en conflicto”. Los roles de género determinan distintas formas de acceso a los RFNM, como se verá en la siguiente sección.

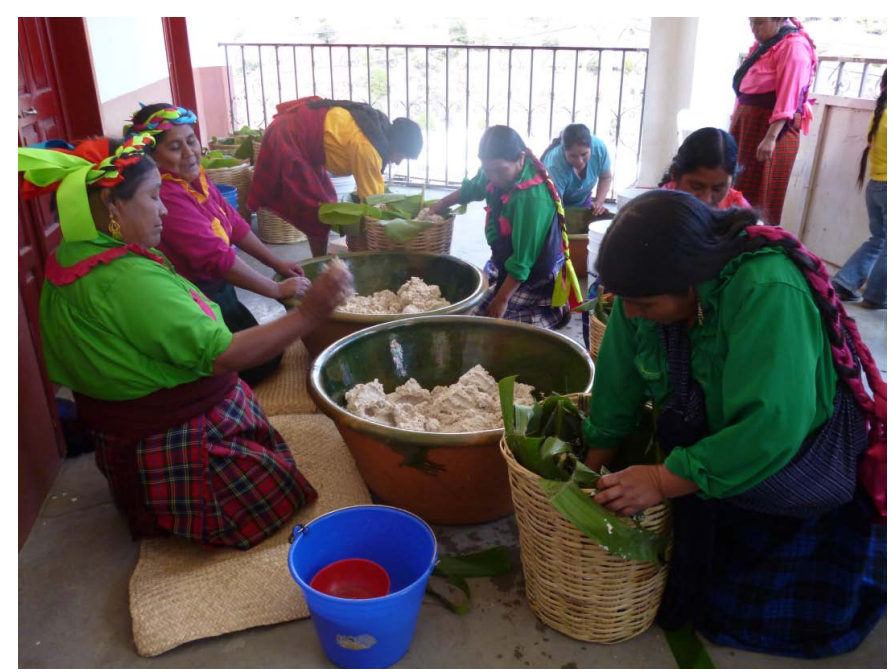

FIGURA 7. Mujeres de SMM preparando los alimentos para la fiesta de la comunidad.

Hombres, mujeres y acceso diferenciado: ¿para la fiesta o para la venta?

El poleo es cosechado de acuerdo a las normas establecidas en la asamblea de bienes comunales. Las mujeres no tienen titularidad de derechos agrarios, ninguna figura en el padrón de comuneros. Esto quiere decir que no tienen voz ni voto en el proceso de toma de decisiones relacionado con el aprovechamiento del poleo. La cosecha del poleo para la fiesta de Año Nuevo no requiere de permiso alguno. De hecho, las autoridades la organizan e instrumentan. Se extraen hasta doce brazadas que se trasladan en camioneta, puesto que hay que repartir ramos a toda persona mayor de 18 años. Se trata de una planta que mantiene viva la estructura de poder masculino, por lo que contribuir a su cosecha es parte de las actividades que los hombres deben hacer en forma de "tequio" o trabajo voluntario.

El uso cotidiano del poleo como alimento o medicina ha hecho que algunas personas lo trasladen al solar para tenerlo a la mano. No es una planta fácilmente adaptable ya que requiere de condiciones ambientales específicas, por ejemplo "tierra de monte" que es rica en materia orgánica y nutrimentos: "no lo planté en esta tierra de aquí del pueblo, sino que lo traje pero juntamente con el abono de allá”. Es necesario traer la mata de la montaña con raíz y 
plantarla debajo de árboles frutales o en espacios con sombra. Durante la temporada de sequía debe regarse una o dos veces por día para mantenerlo fresco; en la temporada de lluvias, los riegos no son necesarios. Existen dos modalidades de siembra: en maceta y en el suelo. En ambos espacios el crecimiento puede resultar favorable, aunque son pocos los solares donde se encontró poleo.

Dado el valor regional de la planta, no es de sorprenderse que sea buscado por gente de otras localidades y tenga valor comercial en mercados de la región. La extracción para la venta sí requiere de autorización del CBC, asunto que aplica tanto a los/as habitantes de la comunidad, como a personas ajenas a ella. Las personas ajenas a la comunidad, además de pedir permiso, deben pagar una cuota de $\$ 150,00$ a $\$ 200,00$ dependiendo de la cantidad requerida. $\mathrm{El} \mathrm{CBC}$ asigna a una persona para que suba con ellos/as y mantenga control sobre la extracción.

Algunos/as habitantes de SMM tienen mayores posibilidades que otras de obtener autorización para comercializar poleo. Este es el caso de las "viudas" que carecen de un proveedor masculino: "vemos que necesitan... mantenimiento de su familia, pues sí se deja... recogerlo un poquito para venderlo". Una de las mujeres entrevistadas así lo constata: "quería uno comer, pero quién lo va a dar, si no sale uno, digo yo". Como en otras partes del mundo (Seligmann, 2001), las mujeres de SMM que comercializan poleo son jefas de familia que han establecido "derechos" sobre determinados productos, los cuales pueden ser comercializados a pequeña escala, en particular si se trata de herbolaria tradicional para uso ritual, alimenticio o medicinal. La representación de las mujeres como vulnerables en el discurso comunitario les beneficia para establecer y defender tales derechos (Martí, 2001).

Sin embargo, hay bastante ambigüedad sobre cantidades y periodicidad de extracción. Aparentemente, el término "poquito" se refiere a dos brazadas. En relación a la periodicidad, un entrevistado señaló que hay que tener cuidado porque "estamos viendo que si lo dejamos así, pa' que la gente lo saque cada ocho días o cada quince días, ya no va a haber, ese es el cuidado que tenemos". La ambigüedad hace que algunas viudas teman atender algunos encargos de poleo. Señala una de ellas: "a veces... encargan a uno por ahí... pues más que se enoja la gente... fuimos a traer poquito, pero poquito, no mucho también, porque se enoja, porque va a pagar multa, por eso tengo miedo". Otra informante considera que la información sobre permisos de extracción es escasa: "no hay información de eso pues, nomás ellos lo informan así, porque les beneficia”.

Las viudas enfrentan estas ambigüedades porque, en SMM como en otras partes del mundo, el bosque es un espacio masculino (FAO, 2007; Shackleton et al., 2011; Mai et al., 2011). "Aquí... mayormente los hombres son los que conocen el bosque, porque van a... trabajar... a cortar pino o a sembrar... cortan ramas de encino... ellos son los que conocen más el bosque que las mujeres pues, las mujeres casi no, no van al bosque". Por el contrario, el espacio de trabajo de las mujeres es la casa, donde la multiplicidad de actividades que realizan diariamente les deja poco tiempo libre (Leach, 1994). Las mujeres de SMM "deben de estar pendientes de las tortillas, comida, que no falte nada en la cocina... los hombres... nomás llegan... quiero mi comida y a comer, no, todo, así es, la vida de los hombres es más fácil que la de las mujeres”. Las viudas extraen poleo de las zonas más cercanas al pueblo: "donde está más cerca, pues se acaba, porque las personas van a cortarlo". Acuden acompañadas, de manera poco frecuente y para extraer cantidades pequeñas debido a las limitaciones para cargar. "Vamos con los niños a veces, pero a veces, pues ese no es trabajo de diario". "Una brazada así nomás... lo que aguante a cargar, como no tengo hombre pa' que lo cargue bastante".

Las diferencias de género en el acceso al poleo son expresiones del orden de género que predomina en SMM. Como planta de alto valor cultural, se utiliza para celebrar la renovación del cabildo y el CBC (ambos poderes masculinos) y las autoridades permiten y organizan su extracción, que de hecho constituye una responsabilidad masculina para con la comunidad. Al mismo tiempo, se reconoce al poleo como un RFNM femenino y se autoriza su extracción para la venta cuando el hombre falta en casa. Las mujeres acuden a parajes cercanos, mientras que 
los hombres van a los más altos donde se encuentra poleo en mayor cantidad y calidad. Los hombres disponen de camioneta, las mujeres sólo de burro o de su espalda para cargar las ramas. Para la fiesta de año nuevo, los hombres extraen hasta doce brazadas; para la venta, las mujeres obtienen, cuando mucho, tres.

La falta de claridad en periodicidad y cantidades en el caso de las viudas ilustra la fragilidad de sus derechos sobre el poleo, ya que estos se definen en ámbitos de toma de decisiones totalmente masculinos. Otro ejemplo de las dificultades que enfrentan las mujeres respecto al uso de los recursos se refiere al tema del agua. Estudios realizados en otras comunidades forestales describen la prohibición de utilizar agua del pueblo para lavar ropa (es forzoso ir al río) o cortar árboles para obtener leña: se "puede ir a la montaña a cortar leña, pero solo las ramas, árboles caídos y troncos secos. Un árbol entero solo lo pueden autorizar los directivos de la parcialidad" (testimonio citado en Gramajo, 1997:82). Sobra decir que las mujeres son las principales responsables de lavar ropa y conseguir leña, y que estas disposiciones, tomadas sin su participación, hacen más arduas sus labores. Es esencial encontrar fórmulas donde la sustentabilidad no implique la exclusión de los principales usuario/as de los recursos.

\section{Trueque y comercio de poleo: aportes femeninos} al bienestar familiar

El mercadeo del poleo sigue dos rutas; en la primera se intercambia por productos de consumo alimenticio y, en la segunda, por dinero en efectivo. A su vez, esta última puede tomar dos formas: comercializar manojos sin un encargo previo o atender pedidos específicos, los cuales en general se hacen para bodas o fiestas comunitarias.

Los principales puntos de trueque o venta son Ayoquezco de Aldama, Zimatlán de Álvarez, Ocotlán de Morelos, Santiago Apóstol, San Antonino Castillo Belasco e incluso la ciudad de Oaxaca. En las tres modalidades, el mercadeo es realizado por mujeres, situación constatada en muchos trabajos sobre RFNM realizados en México y otras partes del mundo (Leach, 1994; Marshall et al.,
2006; Djoudi y Brockhaus, 2011; Mai et al., 2011; Mukasa et al., 2012; Banana et al., 2012).

Según Seligmann (2001), las labores femeninas de venta son una extensión de sus roles domésticos que hacen posible la supervivencia de su familia, entendida no sólo como cuidado físico sino también como generación de ingresos, particularmente en un contexto de escasez económica. El papel de "madres" se realiza tanto en casa como en sitios de venta. La ideología de género se transfiere a los espacios del mercado. Los hombres, como principales proveedores, generalmente tratan de insertarse en actividades mejor pagadas (Leach, 1994). Es así que en la cultura zapoteca de SMM, un hombre "ofreciendo" poleo es mal visto. "Los hombres casi nos da pena, 'ora sí, pa' cargarlo y ofrecerlo... es principalmente las mujeres". La venta de RFNM es considerada una actividad complementaria, inferior a otras que generan mayores ingresos y que generalmente se asocian a los hombres, por ejemplo la siembra de productos agrícolas (Schreckemberg et al., 2006).

Esta situación ha hecho que los aportes del poleo al bienestar familiar sean invisibilizados, a pesar de que el trueque o comercialización de RFNM aporta diversidad a la dieta y muestra la amplia gama de actividades de subsistencia que existen en las comunidades forestales de diversas partes del mundo (Leach, 1994; Cabarle et al., 1997; Wickramasinghe, 1997; De la Peña e Illsey, 2001). Las mujeres de SMM intercambian manojos de poleo por tortillas, tunas, limón, chayote, jitomate, cebolla, pan, tamales, atole, por mencionar sólo algunos de los productos vistos en los mercados o escuchados en las entrevistas (Figs. 8 y 9). Se trata de un ejercicio de reciprocidad que contribuye a la creación de redes femeninas y al fortalecimiento de la autonomía femenina en el ámbito doméstico, ya que reduce la dependencia de los recursos monetarios de otras personas (por ejemplo el esposo) (Leach, 1994; Seligmann, 2001). Esta actividad también funciona como una forma de ahorro al obtener productos de consumo doméstico que no se producen localmente sin tener que gastar el efectivo que las mujeres pudieran tener.

Cuando el poleo es traído para ofertarlo en la plaza, la calidad es una característica importante para su buena 


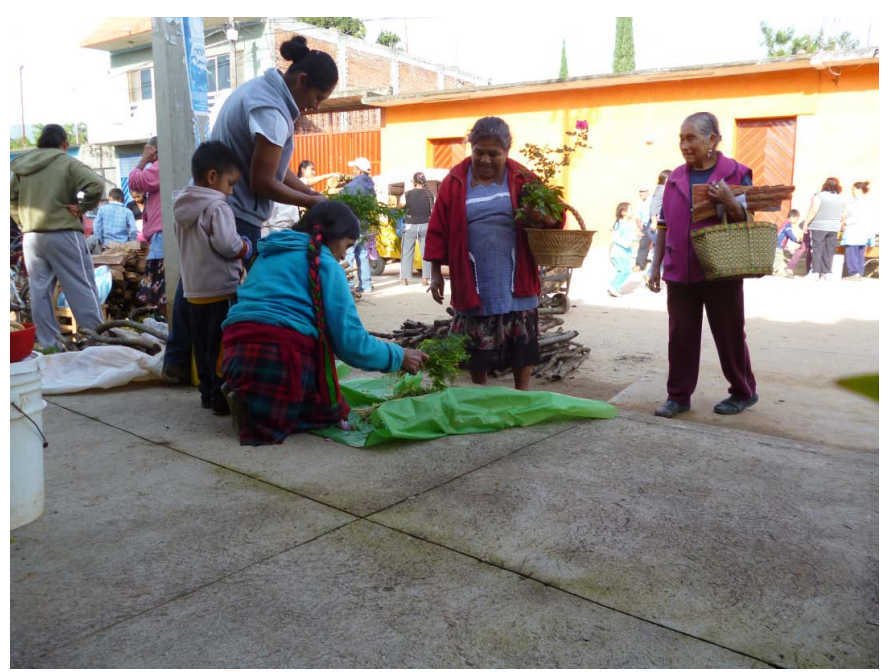

FigurA 8. Mujeres zapotecas de SMM y Ayoquezco de Aldama realizando el trueque.

comercialización; la clientela prefiere tallos derechos, con una longitud de $50 \mathrm{~cm}$ a $80 \mathrm{~cm}$ : "no le van a comprar los que están todos torcidos y feos, se fijan en los que están bonitos, pues, larguitos, bien cortados, en las puntas todas parejitas y eso es lo que se vende". Para mantener la calidad hasta la llegada al mercado es necesario cubrir al poleo con un plástico o follaje de helechos u otras hierbas. Las ramas se hidratan frecuentemente para que no pierdan turgencia. Para mejorar la presentación en el mercado, el poleo se arregla en manojos de cinco a seis tallos.

Los pequeños manojos de poleo se venden "a tres por diez, cinco pesos, depende de cómo esté y de cómo haya... en el mercado". La brazada cuesta \$200,00 o \$250,00 como máximo (pesos mexicanos). En los meses de octubre, noviembre y diciembre, las vendedoras combinan el ramo de poleo con flores silvestres (principalmente orquídeas) para otorgarle mayor presentación y mejorar el precio. Los mayores niveles de venta se realizan en días festivos como Día de Muertos, Navidad y Semana Santa.

El ingreso obtenido por la venta de poleo se utiliza para adquirir productos de consumo doméstico en el mismo mercado y regresar a la comunidad con ellos en lugar de con dinero en efectivo. Esta es una estrategia que utilizan las mujeres para mantener el control sobre sus

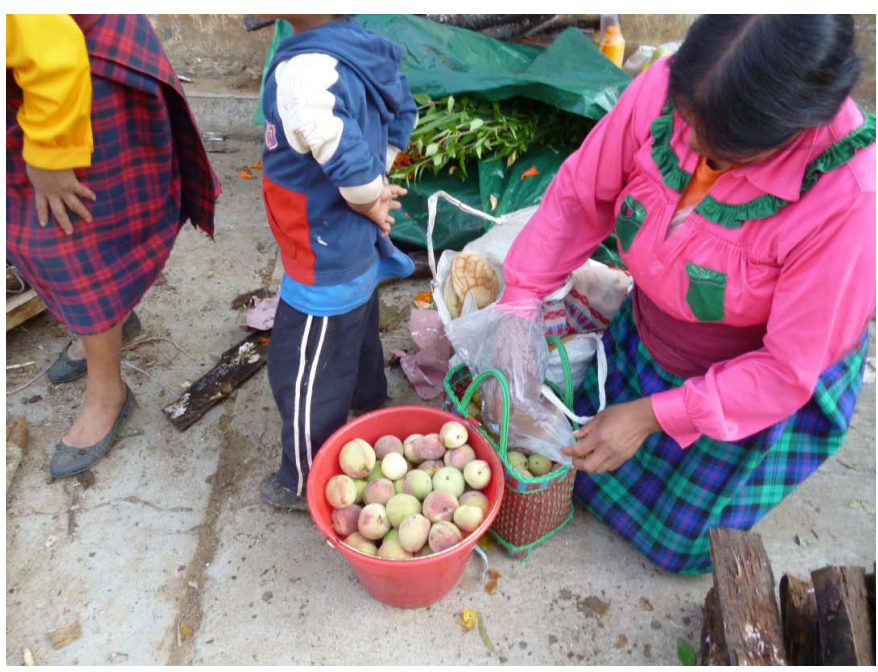

FIGURA 9. Mujer zapoteca de SMM intercambiando poleo y duraznos.

ganancias, como lo han señalado Chávez y Zapata (1995) para otros contextos.

Cuando la venta es por pedido, la clientela deja "una señal” de \$50,00 o \$100,00. Se establece el acuerdo de cuándo y dónde se entregará el producto. Esta dinámica de venta presenta mejores oportunidades porque es segura, las cantidades solicitadas son mayores y el precio es más alto: "se usa mucho ora sí [que] en las fiestas, cuando te encargan, entonces sí es cuando le va bien al que corta, porque... son como de diez a quince tercios [brazadas] es cuando lo encarga". Sin embargo, el inconveniente es que las ventas de este tipo son esporádicas. En esta modalidad de venta sí participan algunos hombres ya que los ingresos obtenidos son más altos y la cosecha ocasional no trastoca sus otras labores ni su imagen como proveedor principal del hogar.

\section{CONCLUSIONES}

El poleo crece y se desarrolla de manera discontinua, bajo una cobertura de dosel cerrada, en suelos moderadamente ácidos y ricos en materia orgánica. Forma parte del sotobosque presente en las partes altas de las montañas donde predomina el bosque de encino y pino-encino. La altura a la cual se distribuye se caracteriza por presentar tempera- 
turas frías la mayor parte del año. Esto sugiere que la especie prospera mejor a altitudes elevadas. Las partes altas son menos vulnerables a su extracción, en comparación con los parajes ubicados cerca de la comunidad. Quedan preguntas pendientes sobre el traslado a los solares, sobre todo porque se trata de una planta multipropósito que las mujeres aprecian tener a la mano.

La presencia de la especie en el territorio municipal no sólo depende de las condiciones ecológicas, sino también del manejo localmente implantado. Los saberes locales sobre las prácticas de aprovechamiento de la especie, se relacionan directamente con sus etapas de crecimiento. Durante la temporada de lluvias se permite que la planta rebrote para lo cual se disminuye al máximo su cosecha, esto permite el buen crecimiento y desarrollo de los brotes vegetativos; solo se cosechan los tallos bien desarrollados, en crecimiento vegetativo cuya longitud varía de $50 \mathrm{~cm}$ a $80 \mathrm{~cm}$. Se evita al máximo cosechar tallos en floración para proteger la fase reproductiva y asegurar el desarrollo y maduración de semillas que garanticen la reproducción natural de la especie. El corte se realiza con la mano porque esto favorece el rebrote de la planta. También se constató que ciertas actividades (por ejemplo la roza para la siembra de maíz, la cosecha de madera) fomentan su crecimiento. Estos dos últimos temas requieren de mayor profundización en trabajos futuros.

Hombres y mujeres hacen distintos usos del poleo. Es una planta de uso ritual y ornamental utilizada en fiestas comunitarias como son: mayordomías, bodas, festividades navideñas y Año Nuevo. También se utiliza como alimento (té, condimento, verdura y agua fresca) y medicina para atender malestares estomacales, partos, fiebres y resacas. Los usos públicos (ritual y ornamental) son masculinos, debido a la asociación cultural entre los hombres y el espacio público. El uso doméstico y cotidiano del poleo es de las mujeres, porque son ellas las que guisan y están al cuidado de la salud familiar. En este sentido, los conocimientos culinarios del poleo son fundamentalmente femeninos. En los saberes curativos hay diferencias de género en lo que se refiere a los malestares que la planta puede controlar (resaca versus trabajo de parto) y de edad entre las mujeres. Esto es evidencia, una vez más, de la riqueza del sistema de saberes locales relacionados con la planta. Queda pendiente determinar con mayor exactitud las propiedades químicas que le dan sus capacidades curativas.

El uso que se le da al poleo está ligado a sus formas de acceso. Cuando se necesita para la fiesta de Año Nuevo, son las mismas autoridades masculinas quienes organizan la cosecha y reparten los ramos a los y las asistentes al evento, como un "símbolo de alegría". En otros casos, en particular si se es fuereño, es necesario solicitar autorización y/o pagar una cuota para cortar poleo bajo la supervisión de las autoridades. Las viudas de SMM son un grupo especial, ya que están autorizadas para cosechar poleo para el sustento, pero las cantidades y la regularidad no están bien definidas y mucho menos consensuadas con ellas. A partir de los testimonios se concluye que cosechan cerca del pueblo y en cantidades menores que los hombres que organizan fiestas porque, a diferencia de ellos, no disponen de camioneta sino sólo de burros o de sus propias espaldas para el traslado. Queda pendiente determinar el sistema de sanciones existente en caso de no acatar los acuerdos y su impacto en las actividades de extracción de hombres y mujeres.

Se detectaron tres formas de mercadeo: trueque, venta por oferta y por pedido. La primera y la segunda son realizadas por mujeres mientras que en la tercera participan algunos hombres dado su carácter esporádico y de mayores ingresos. El poleo ingresa al mercado regional de los Valles Centrales de Oaxaca con muy poco valor agregado y en pequeños volúmenes. Sin embargo, la planta constituye, como muchos otros RFNM, una de las pocas fuentes de ingresos que tienen las mujeres de SMM. Cuando es intercambiado por otros productos, contribuye a la diversidad dietética y al bienestar de las familias, dado el carácter eminentemente forestal de la comunidad.

Este trabajo aporta al conocimiento de los RFNM a través del análisis de los conocimientos locales y de los roles de género involucrados en el aprovechamiento de uno de los 1000 RFNM que se utilizan en el país. El poleo es de gran valor para los pueblos indígenas de Oaxaca y 
otros estados. Sin duda, debe haber muchas más plantas cuyo valor ritual, ornamental, alimenticio y medicinal contengan sistemas de conocimientos y dinámicas de género específicas. Es indispensable hacer más investigación sobre ellas, caso por caso, para seguir deshilvanando las particularidades de cada una, y así poder formular políticas que visibilicen y atiendan por igual las necesidades de hombres y mujeres que habitan en las muy diversas comunidades forestales del país.

\section{REFERENCIAS}

Aguilar, L. 2007. ¿Por qué las mujeres están ausentes en el manejo y conservación de la Biodiversidad? In: L.M. Donato, E.M. Escobar, P. Escobar, A. Pazmiño y A. Ulloa, eds. Mujeres indígenas, territorialidad y biodiversidad en el contexto latinoamericano. Universidad Nacional de Colombia. Bogotá, Colombia. p:223-230.

Aguilar-Ramírez, J.M. 2002. Especiación recombinacional y relaciones filogenéticas en Satureja macrostema var. Laevigata. Tesis de doctorado. Área de Ciencias Agrícolas y Forestales. Universidad de Colima. Tecomán Colima, México. 140 p.

Aguilar, R.M., H.M. Muñoz, M. Hernández, M.A. Bello y R. Salgado. 2005. Observaciones fenológicas de Satureja macrostema (Benth.) Briq., en dos localidades de Michoacán, México. Revista Ciencia Forestal en México 29(96):91-109.

Ahenkan, A. y E. Boon. 2011. Non-timber forest products farming and empowerment of rural women in Ghana. Environment, Development and Sustainability 13(5):873-878.

Alexiades, M.N. y P. Shanley. 2004. Productos forestales, medios de subsistencia y conservación. In: M.N. Alexiades y P. Shanley, eds. Productos forestales, medios de subsistencia y conservación: estudios de caso sobre sistemas de manejo de productos forestales no maderables. Centro para la Investigación Forestal Internacional. Jakarta, Indonesia. p:1-22.

Alonso-Carrillo, N. 2009. Actividad antioxidante de Satureja macrostema. Tesis de maestría. Instituto Politécnico Nacional. México D. F. 70 p.
Antinori, C. 2007. Integración vertical en las empresas forestales comunitarias de Oaxaca. In: D. Bray, L. Merino y D. Barry, eds. Los bosques comunitarios de México. Instituto Nacional de Ecología. México, D.F. p:303-342.

Banana, A., M. Bukenya, E. Arinaitwe, B. Birabwa y S. Ssekindi. 2012. Gender, tenure and community forests in Uganda. Working Paper 87, CIFOR. Bogor, Indonesia. 36 p.

Bray, D. B., L. Merino Pérez y D. Barry. 2007. El manejo comunitario en sentido estricto: las empresas comunitarias de México. In: D. B. Bray, L. Merino Pérez y D. Barry, eds. Los bosques comunitarios de México. Instituto Nacional de Ecología, México, D. F. p: 21-49.

Cabarle, B., F. Chapela y S. Madrid. 1997. El manejo forestal comunitario y la certificación. In: L. Merino, ed. El manejo forestal comunitario en México y sus perspectivas de sustentabilidad. CRIM/UnAm, Cuernavaca, México. p: 17-33.

Challenger, A. y J. Soberón. 2008. Los ecosistemas terrestres. In: J. Soberón, G. Halfter y J. Llorente-Bousquets, comps. Capital natural de México vol. I: conocimiento actual de la biodiversidad. Conabio, México, D. F. p: 87-108.

Chapela, G. y S. Madrid. 2007. Lineamientos básicos para una política forestal de Estado. In: J.L. Calva, ed. Sustentabilidad y desarrollo ambiental. unam, Cámara de Diputados y Miguel Ángel Porrúa, México D.F. p: 80-88.

Chávez, G. E. y E. Zapata Martelo. 1995. Mujer rural, comercio y conocimiento tradicional: el caso de las vendedoras de tempesquistle en los valles de Tehuacán, Puebla y Orizaba, Veracruz. In: E. Zapata, P. Alberti y M. Mercado, coords. Desarrollo rural y género. Avances y problemas de proyectos microeconómicos de mujeres. Colegio de Postgraduados, Texcoco, México. p: 20-45.

Conapo (Consejo Nacional de Población). 2011. Índice de marginación por entidad federativa y municipio 2010. Consejo Nacional de Población. México, D. F. 310 p.

De la Peña, Gustavo y Catarina Illsey, 2001. Los productos forestales no maderables. Su potencial económico, social y de conservación. En La Jornada, http://www.jornada.unam. mx/2001/08/27/eco-a.html. Acceso 14 de junio de 2013.

De Walt, B.R. 1999. Combining indigenous and scientific knowledge to improve agriculture and natural resource 
management in Latin America. In: F.J. Pichón, J.E. Uquillas y J. Frechione, eds. Traditional and modern natural resource management in Latin America. University of Pittsburgh Press, EUA. p:101-121.

Djoudi H. y M. Brockhaus. 2011. Is adaptation to climate change gender neutral? Lessons from communities dependent on livestock and forests in northern Mali. International Forestry Review 13(2):123-135.

FAO (Food and Agriculture Organization). 2007. Gender mainstreaming in forestry in Africa. FAO, Forest Policy Working Paper 18, Roma, Italia. 53 p.

Gramajo, S.E. 1997. Autogestión comunitaria de recursos naturales. Estudio de caso de Totonicapan. FLACSO, Guatemala, Guatemala. 109 p.

INE (Instituto Nacional de Ecología). 2009. México: Cuarta Comunicación Nacional ante la Convención Marco de las Naciones Unidas sobre el Cambio Climático. Semarnat e Instituto Nacional de Ecología, México. 274 p.

INEGI (Instituto Nacional de Estadística y Geografía). 2010. Censo de Población y Vivienda 2010. Instituto Nacional de Estadística y Geografía, México D.F.

INEGI (Instituto Nacional de Estadística y Geografía). 2005. Prontuario de información geográfica municipal de los Estados Unidos Mexicanos. San Miguel Mixtepec, Oaxaca, clave 20271. INEGI, México. 9 p.

Labrador Moreno, J. 2001. La materia orgánica en los agrosistemas. Ediciones Mundi-Prensa. España. 293 p.

Leach, M. 1994. Rainforest relations. Gender and resource use among the Mende of Gola, Sierra Leone. Smithsonian Institution Press, Washington D.C. 272 p.

Mai, Y.H., E. Mwangi y M. Wan. 2011. Gender analysis in forestry research. Looking back and thinking ahead. International Forestry Review 13(2):245-258.

Marshall, E., K. Schreckember y A. Newton. 2006. Introducción y marco del estudio. In: E. Marshall, K. Schreckember y A. Newton, eds. Comercialización de productos forestales no maderables. Factores que influyen en el éxito. PNUMA WCMC, Cambridge, Reino Unido. p: 12-20.

Martí, J. 2001. Nineteenth-century views of women's participation in Mexico's markets. In: J.L. Seligmann, ed., Women traders in cross-cultural perspective. Stanford University Press. Stanford, California, EUA. p:27-44.

Martínez, R. y O. Masera. 2012. Escenarios de mitigación de carbono hacia 2030. Contribución de las opciones del sector forestal en México. In: J.L. Calva, ed., Cambio climático y políticas de desarrollo sustentable. Juan Pablos y Consejo Nacional de Universitarios. México D.F. p:149-165.

Merino L., G. Ortiz y A. E. Martínez (en prensa). La producción forestal. In: L. Merino y G. Ortiz, coords. Encuentros y desencuentros. Las comunidades forestales y las políticas públicas en tiempos de transición. UNAM y Miguel Ángel Porrúa, México D.F. p:48-83.

Mukasa, C., A. Tibazalika, A. Mango y H. Muloki. 2012. Gender and forestry in Uganda: policy, legal and institutional frameworks. Working Paper 89. CIFOR, Bogor, Indonesia. $40 \mathrm{p}$.

Musálem, M.A. 2007. Políticas públicas para el desarrollo del sector forestal en México. In: J.L. Calva, ed. Desarrollo agropecuario, forestal y pesquero. Universidad Nacional Autónoma de México-Miguel Ángel Porrúa. México, D.F. p:333-347.

Pérez-Gutiérrez, R.M. 2012. Antihepatotoxic, nephroprotective, and antioxidant activities of phenolic compounds from Satureja macrostema leaves against carbon tetrachloride-induced hepatic damage in mice. Medicinal Chemestry Research 22(4): 1846-1855.

Quiroz, C. 1999. Local knowledge systems in Latin America: current trends and contributions toward sustainable development. In: F.J. Pichón, J.E. Uquillas y J. Frechione, eds. Traditional and modern natural resource management in Latin America. University of Pittsburgh Press, Pittsburgh, EUA. p:212-232.

Rzedowski, J. y G. Calderón de Rzedowski. 2010. Flora fanerogámica del Valle de México. Instituto de Ecología y Comisión Nacional para el Conocimiento y Uso de la Biodiversidad, México D. F. 975 p.

Sánchez Vélez, A. y R.M. García Núñez. 2008. La situación del subsector forestal en México ante el TLCAN, retos y oportunidades, 10 años después. In: J.A. Ávila, A. Puyana y J. Romero, eds. Presente y futuro de los sectores ganadero, forestal y de la pesca mexicanos en el contexto del TLCAN. 
El Colegio de México y Universidad Autónoma Chapingo. México D.F. p:303-367.

Sandoval-Casilimas, C.A. 2002. Investigación cualitativa. Instituto Colombiano para el Fomento de la Educación Superior, ICFES. Bogotá, Colombia. 311 p.

Schmink, M. 1995. La matriz socioeconómica de la deforestación. In: M.F. Paz, ed. De bosques y gente. Aspectos sociales de la deforestación en América Latina. CRIM/ UNAM. Cuernavaca, México. p:17-51.

Schreckemberg, K., E. Marshall y D. Willen te Velde. 2006. Comercialización de PFNM y pobreza rural ¿Más que una red de seguridad? In: E. Marshall, K. Schreckemberg y A.C. Newton, eds. Comercialización de productos forestales no maderables. Factores que influyen en el éxito. PNUMA WCMC. Cambridge, Reino Unido. p:76-82.

Schreckemberg, K. y E. Marshall. 2006. Los PFNM y las mujeres ¿Mejora el ingreso y la posición social? In: E. Marshall, K. Schreckemberg y A.C. Newton, eds. Comercialización de productos forestales no maderables. Factores que influyen en el éxito. PNUMA WCMC. Cambridge, Reino Unido. $\mathrm{p}: 83-95$.

Seligmann, L.J. 2001. Women Traders in Cross-Cultural perspective. Stanford University Press, Stanford California, EUA. 308 p.

Semarnat (Secretaría de Medio Ambiente y Recursos Naturales). 2001. Norma Oficial Méxicana (NOM) NOM-021-RECNAT-2000. Especificaciones de fertilidad, salinidad y clasificación de suelos. Estudios, muestreo y análisis. Publicado en el diario oficial de la federación el 31 de diciembre de 2001. México D.F. 85 p.

Semarnat (Secretaría de Medio Ambiente y Recursos Naturales). 2009. Programa de Manejo Forestal 2008-2018 de San Miguel Mixtepec, Oaxaca. Comisariado de Bienes Comunales de SMM-Semarnat.
Shackleton, S., F. Paumgarten, H. Kassa, M. Husselman y M. Zida. 2011. Opportunities for enhancing poor women's socioeconomic empowerment in the value chains of three African non-timber forest products (NTFPs). International Forestry Review 13(2):136-151.

Turner, B. L. 2008. Taxonomic status of Clinopodium macrostemun (Lamiaceae). Phytologia 90(3):411-413.

Umafor (Unidad de Manejo Forestal Regional). 2009. Estudio Regional Forestal. Unidad de Manejo Forestal Regional No. 2012, Sierra Sur, Zimatlán, Sola de Vega, Valles Centrales, A.C. Oaxaca. 453 p.

Valladares, F. 2006. La disponibilidad de luz bajo el dosel de los bosques y matorrales ibéricos estimada mediante fotografía hemisférica. Ecología (20):11-30.

Vázquez-García, V., L. Godínez-Guevara, M. Montes-Estrada, M. Montes-Estrada y A. S. Ortiz-Gómez. 2004. Los quelites de Ixhuapan, Veracruz: disponibilidad, abastecimiento y consumo. Agrociencia 38(4):445-455.

Villaseñor, J.L. 2010. El bosque húmedo de montaña en México y sus plantas vasculares: catálogo florístico-taxonómico. Conabio-UnAm. México, D.F. 40 p.

Wickramasinghe, A. 1997. Women, development and sectors pertaining to land and forestry. In: A., Wickramasinghe, ed., Land and Forestry. Women's local resource-based occupations for sustainable survival in South Asia. CORRENSA. Sri Lanka. p:1-50.

World Bank. 2009. Gender in Agriculture Sourcebook. The World Bank. Washington, DC. 764 p.

Manuscrito recibido el 19 de junio de 2013

Aceptado el 11 de febrero de 2014

Este documento se debe citar como:

Ortega-Ortega, T. y V. Vázquez-García. 2014. Satureja macrostema: situación ambiental, conocimiento local y roles de género. Madera y Bosques 20(2):71-86. 